\title{
Perfil da pessoa com deficiência no mercado de trabalho na cidade de São Carlos-SP
}

Aline Aparecida Veltrone* Maria Amélia Almeida**

\section{Resumo}

O ingresso da pessoa com deficiência no mundo do trabalho pode ser considerado uma forma de inclusão social. No Brasil, há legislação favorável ao ingresso e à permanência da pessoa com deficiência no mercado de trabalho. Os estudos realizados sobre essa temática evidenciam correlação entre nível de escolaridade, qualificação profissional e condições de ingresso. Contudo, seria importante descrever como os diferentes tipos de deficiência estão relacionados com estas variáveis. Este estudo teve como objetivo caracterizar a inserção da pessoa com deficiência no mercado de trabalho em relação ao tipo de deficiência, nível de escolaridade, qualificação profissional e ocupação atual. Participaram do estudo 92 funcionários com diferentes tipos de deficiência provenientes de quatro empresas localizadas na cidade de São Carlos-SP, com mais de cem funcionários cada. Para a coleta de dados, foi utilizado um questionário com perguntas abertas e fechadas e a análise dos dados foi feita de forma quantitativa. Os resultados indicaram que o ingresso profissional da pessoa com deficiência é feito de acordo com as regras que regem o mercado de trabaIho atual, tais como: escolaridade, produtividade e competitividade.

Palavras-chave: Educação Especial. Pessoas com deficiência. Mercado de trabalho. Inclusão social.

\section{Profile of person with disabilities in the work market in São Carlos-SP}

\begin{abstract}
The insertion of people with disabilities in the job world can be considered one way for social inclusion. In Brazil, there is legislation to support the insertion and permanence of people with disabilities in the job market. The studies done about this issue, demonstrate correlation between level of schooling, professional qualification and insertion condition. However, it would be important to identify how different types of disabilities are related with these variables. The aim of this

\footnotetext{
* Doutoranda do Programa de Pós-graduação em Educação Especial da Universidade Federal de São Carlos (UFSCar). São Carlos, São Paulo, Brasil.

** Professora Doutora do departamento de psicologia e Programa de Pós-graduação em Educa-
} ção Especial da Universidade Federal de São Carlos (UFSCar). São Carlos, São Paulo, Brasil.
\end{abstract}


research was to characterize the insertion of people with disabilities in the job market related to the level of schooling, professional qualification and present occupation. The participants were 92 employees with different disabilities from four companies located in the city of São Carlos-SP with more than 100 employees each. The data collection procedures involved a questionnaire with open and closed questions and the data was analyzed in a quantitative way. The results evidenced that the professional insertion of people with disabilities is done according to the rules of the present job market, such as: schooling level, productivity and competition.

Keyword: Special education. People with disabilities. Job market. Social inclusion.

\section{Introdução}

Para o grupo de pessoas consideradas deficientes, historicamente foi imposta a condição de inferioridade e incapacidade, a qual acabava por justificar a sua segregação e exclusão dos espaços comuns da sociedade. Dentre estas práticas de exclusão e segregação, muitas vezes foi negada a inserção da pessoa com deficiência no mundo do trabalho, porque se considerava que elas tinham características que as distinguiam das demais e que, consequentemente, as tornavam ineficientes para participarem do mercado de trabalho (AMARAL, 1994; SILVA, 2000, JANUZZI, 2004; TANAKA, 2007).

Práticas e concepções relacionadas a esta definição de incapacidade da pessoa com deficiência foram mudando ao longo dos tempos. Com relação à concepção de deficiência vigente, a Coordenadoria Nacional Para a Integração da Pessoa Portadora de Deficiência (CORDE), a definiu no Decreto n. 3.298/99 como sendo: "Toda perda ou anormalidade de uma estrutura ou função psicológica, fisiológica ou anatômica que gere incapacidade para o desempenho da atividade, dentro do padrão considerado normal" (BRASIL, 1999).

Dentre as ações propostas para a inclusão social das pessoas com deficiência, destaca-se a inclusão via mercado de trabalho. O trabalho é considerado importante porque pode ser considerado o meio pelo qual o homem atua na sua realidade, modifica-a, transforma-a e constrói sua identidade pessoal e social, além de ser um meio capaz de garantir às pessoas participação nos espaços comuns da sociedade, bem como determinante da auto-estima e consciência de dignidade das pessoas (BRASIL, 2003).

O trabalho foi definido como direito fundamental do homem a partir da Declaração Universal dos Direitos Humanos, sancionado pela ONU em 10 de dezembro de 1948, a qual estabelece que: "Todo homem tem direito ao trabalho, à livre escolha do emprego, a condições justas e favoráveis de trabalho e proteção contra o desemprego". No Brasil, a Constituição Federal de 1988 defende no seu artigo $7^{\circ}$ "Proibição de qualquer discriminação no tocante a salário e critérios de admissão do trabalhador portador de deficiência" e no artigo. $37^{\circ}$ que 
"A lei reservará percentual dos cargos e empregos públicos para as pessoas portadoras de deficiência e definirá os critérios de sua admissão". A partir disso, compreende-se que as pessoas com deficiência devem ter os mesmos direitos que os demais e, portanto, devem experenciar iguais oportunidades de ingresso no mercado de trabalho.

O Decreto $n^{\circ} 3.298$ que regulamenta a Lei $n^{\circ} .7853$ que dispõe sobre a Política Nacional para a Integração da Pessoa Portadora de Deficiência estabelece o compromisso do estado com a formação profissional da pessoa com deficiência, qualificação profissional e ingresso no mercado de trabalho (BRASIL, 1999). O referido decreto também defende que deve ser garantida a equiparação de oportunidades à pessoa com deficiência no acesso ao trabalho, a qual pode ser tanto pela inserção da pessoa no mercado de trabalho ou sua incorporação ao sistema produtivo mediante regime especial de trabalho protegido. No seu artigo $35^{\circ}$ o Decreto assim define as modalidades previstas para a inserção laboral da pessoa com deficiência:

I - Colocação competitiva: processo de contratação regular, nos termos da legislação trabalhista e previdenciária, que independe da adoção de procedimentos especiais para sua concretização, não sendo excluída a possibilidade de utilização de apoios especiais;

II - Colocação seletiva: processo de contratação regular, nos termos da legislação trabalhista e previdenciária, que depende da adoção de procedimentos e apoios especiais para a sua concretização e;

III - Promoção do trabalho por conta própria: processo de fomento da ação de uma ou mais pessoas, mediante trabalho autônomo, cooperativado ou em regime de economia familiar, com vista à emancipação econômica e pessoal (BRASIL, 1999).

No que diz respeito à equiparação de oportunidades, a legislação também instituiu reserva de até $20 \%$ das vagas de concurso público para as pessoas com deficiência e a reserva de cotas para as pessoas com deficiência, variando de 2 a $5 \%$ junto às empresas privadas com mais de 100 funcionários (BRASIL, 1999).

Temos uma legislação bastante favorável para o ingresso e permanência da pessoa com deficiência no mercado de trabalho. Contudo, a média de empregabilidade da pessoa com deficiência é de apenas 2,05\%, o que leva a questionar se existe efetivamente de viabilidade de mecanismos socais e governamentais que garantam acesso ao emprego às pessoas com deficiência (ARAÚJO; SCHMIDT, 2006).

A literatura a seguir evidência que as condições sociais, econômicas e culturais nas quais se encontram as pessoas com deficiência podem comprometer a qualidade da sua inserção no mercado de trabalho. 
Um estudo realizado por Lancillotti (2003) teve por objetivo buscar o perfil do trabalhador com deficiência que está sendo empregado nas empresas. Por meio de um questionário estruturado, a pesquisadora identificou que o perfil do trabalhador é composto da grande maioria das pessoas com deficiência física, baixos índices de escolaridade e qualificação profissional, e, quanto a funções exercidas, a maioria realiza atividades de auxiliares em detrimento de atividades de supervisão. Além disso, ao se estudar o ingresso da pessoa com deficiência no mercado de trabalho é também importante considerar o contexto, que atualmente é marcado pelo sistema capitalista, pela crise no mercado de trabalho, redução de postos de trabalho e salários, pela falta de profissionais qualificados de acordo com as exigências do mercado, entre outros.

Ferreira et al (2006) realizou um estudo com o objetivo de verificar o estado da arte a respeito das pesquisas sobre a profissionalização da pessoa com deficiência. Os autores tiveram como objetivo investigar as tendências de pesquisas sobre profissionalização das pessoas com deficiência no Brasil. $\mathrm{O}$ tema sobre a profissionalização apareceu em 18 dissertações de mestrado e em geral os objetivos abordados foram: descrição e análise da formação profissional e dos programas direcionados para indivíduos com deficiência em oficinas de preparação para o trabalho em instituições especializadas; descrição e análise do processo de inserção e integração de pessoas com deficiência mental no mercado competitivo de trabalho e estudos sobre a opinião dos indivíduos com deficiência, de seus pais e profissionais com relação ao trabalho. Os resultados evidenciam a precariedade dos programas vocacionais realizados nas instituições especializadas e a desvinculação destes à realidade do trabalho competitivo, em especial para as pessoas com deficiência mental. Além disso, da falta de qualificação profissional, as pessoas com deficiência também possuem baixa-escolaridade. O preconceito e o estigma com relação à deficiência também aparecem enquanto um fator que pode comprometer a inserção da pessoa com deficiência no mercado de trabalho. Os autores discutem ainda a necessidade de que a preparação da pessoa com deficiência para o mercado de trabaIho seja feita de acordo com as qualidades e competências exigidas pelo mercado de trabalho, além da importância da orientação para mudar as representações negativas, de preconceito e incapacidade com relação à pessoa com deficiência.

Um estudo realizado por Manzini e Tanaka (2005) teve como objetivo identificar o ponto de vista dos empregadores sobre as pessoas com diversos tipos de deficiência, o seu trabalho e a sua admissão como funcionário de uma empresa. Para a coleta de dados realizaram entrevista por meio de um roteiro semi-estruturado. Os resultados indicam que a contratação dos funcionários com algum tipo de deficiência ocorreu, principalmente, pela obrigatoriedade da lei de cotas. Apesar de os empregadores acreditarem no potencial das pessoas com deficiência de exercerem uma ocupação, eles ainda viam muitas dificuldades no processo, especialmente em virtude da atribuída incapacidade da pessoa; falta de escolaridade e de interesses e falta de preparação profissional; o que acabava gerando uma baixa qualificação profissional e ingresso no mercado de trabalho. 
Em outro estudo, Araújo e Schmidt (2006) tiveram como objetivo levantar, junto às empresas com mais de 100 funcionários e com as instituições que atendem jovens e adultos com necessidades especiais, quais as práticas que vêm sendo adotadas para a inclusão destas pessoas no mercado de trabaIho e as eventuais dificuldades encontradas nesse processo. A pesquisa foi realizada na cidade de Curitiba-PR e a coleta de dados foi feita por meio de entrevista com roteiro semi-estruturado junto às empresas e com as instituições. Os resultados do estudo evidenciam que o maior empecilho para a contratação e permanência das pessoas com necessidades especiais é a baixa escolarização e qualificação profissional. Além disso, os resultados evidenciam que muitas vezes as instituições que preparam esses jovens e adultos para ingresso no mercado de trabalho não se preocupam com a escolarização e tendem a focar suas atividades na capacitação profissional que envolve as habilidades básicas para o trabalho e que eventualmente podem diferir das esperadas pelas empresas.

Com relação à qualidade do ingresso da pessoa com deficiência no mercado de trabalho, a literatura identifica também a importância do emprego apoiado, especialmente para os casos de deficiência mental, para que as pessoas possam vencer as barreiras impostas, e para que tenham o suporte necessário para garantir a qualidade do desempenho do trabalhador no ambiente de trabalho e, consequentemente, para ajudá-lo a obter funções e ocupações que permitam ascensão profissional e melhoras condições no trabalho (BRADY, 2002). No Brasil, a possibilidade do emprego apoiado para pessoas com deficiência mental é ainda pouco utilizada e isso pode comprometer a qualidade da inserção da pessoa com deficiência no trabalho (FERREIRA et al, 2006; ARAÚJO, ESCOBAL; GOYOS, 2006).

Com base nos estudos apresentados, percebe-se uma forte relação entre nível de escolaridade, qualificação profissional e a qualidade do ingresso da pessoa com deficiência no mercado de trabalho, considerando entre elas as ocupações desempenhadas pelo trabalhador. Também persiste a problemática dos relacionamentos, visto que em muitas situações prevalecem concepções estereotipadas da incapacidade da pessoa com deficiência que pode comprometer a qualidade da sua inserção no mercado de trabalho visto que ainda são vistos com preconceito pelos seus empregadores e também por seus companheiros de trabalho. No sentido de contribuir para o quadro teórico acerca do perfil da pessoa com deficiência que ingressa no mercado de trabalho, este estudo teve por objetivo caracterizar a inserção da pessoa com deficiência no mercado de trabalho em relação ao tipo de deficiência, nível de escolaridade, qualificação profissional e ocupação atual.

Em termos científicos a realização do estudo se justifica porque ele fornecerá informações para contribuir com a produção de conhecimentos a respeito do ingresso da pessoa com deficiência no mercado de trabalho. Com relação às contribuições sociais, o estudo é importante uma vez que para que se assegure uma inserção da pessoa com deficiência no mercado de trabalho 
há que se explorar, primeiramente, as alternativas de emprego existentes, identificando especialmente suas tendências e particularidades.

\section{2 método}

\subsection{Participantes}

Foram coletados dados de 92 pessoas com deficiência que estão no mercado de trabalho formal. Participaram do estudo 3 representantes do setor de recursos humanos e uma enfermeira do trabalho. O quadro abaixo exemplifica as características das empresas participantes do estudo:

Quadro 1. Características das empresas participantes do estudo

\begin{tabular}{|c|c|c|c|c|c|}
\hline Empresa & Ramo & $\begin{array}{c}\text { N. fun- } \\
\text { cionários }\end{array}$ & $\begin{array}{c}\text { N. Fun- } \\
\text { cionários } \\
\text { com } \\
\text { deficiência }\end{array}$ & $\begin{array}{c}\text { Tempo que } \\
\text { empresa assumiu } \\
\text { compromisso coma } \\
\text { lei de cotas }\end{array}$ & Contato \\
\hline E1 & Indústria & 592 & 24 & 5 & $\begin{array}{c}\text { Recursos } \\
\text { humanos }\end{array}$ \\
\hline E2 & Indústria & 225 & 4 & 2 & $\begin{array}{c}\text { Recursos } \\
\text { humanos }\end{array}$ \\
\hline E3 & Comércio & 180 & 3 & 5 & $\begin{array}{c}\text { Recursos } \\
\text { humanos }\end{array}$ \\
\hline E4 & Indústria & 1400 & 62 & 14 & $\begin{array}{c}\text { Enfermeira do } \\
\text { trabalho }\end{array}$ \\
\hline
\end{tabular}

\subsection{Local}

O estudo foi realizado na cidade de São Carlos-SP. O município encontra-se na região central do estado de São Paulo e atualmente conta com uma população de cerca de 212.956 habitantes. A cidade de São Carlos é considerada a capital da tecnologia por conta de duas grandes Universidades ${ }^{1} \mathrm{e}$ outros importantes centros de pesquisa localizados no município. A atividade industrial é marcada pela presença de grandes indústrias, tais como de motores, compressores, geladeiras e fogões, máquinas, além de outras empresas de médio e pequeno porte.

\subsection{Instrumento}

Foi utilizado um questionário estruturado desenvolvido com base no estudo de Redondo (1990) e Lancillotti (2003). O questionário abrangia os se- 
guintes itens: tipo de deficiência do funcionário; nível de escolaridade; qualificação profissional; ocupação no mercado de trabalho e adequação do mercado de trabalho.

\subsection{Procedimentos de coleta de dados}

Etapa inicial: Viabilização das condições de campo

A pesquisa foi submetida à aprovação pelo Comitê de Ética em Pesquisas com Seres Humanos da Universidade Federal de São Carlos-UFSCar. Após a aprovação do projeto, foi feita a seleção das empresas elegíveis para o estudo. Tendo em vista que o objetivo do estudo era caracterizar a pessoa com deficiência que já estava participando do mercado de trabalho, optou-se por inicialmente selecionar informalmente, ou seja, por meio de contato com outros pesquisadores da Universidade Federal de São Carlos-UFSCar, as empresas que já tinha em seu quadro de funcionários pessoas com algum tipo de deficiência. Foram identificadas oito empresas.

Procedimentos de coleta e análise de dados

Foi feito um contato (via telefone) com o representante do setor de recursos humanos das empresas elegíveis para expor os objetivos do estudo e para obter a anuência de participação. Após este contato inicial, as empresas pediram para que a pesquisadora enviasse a proposta de estudo via e-mail. Das oito empresas selecionadas, quatro autorizaram a realização de estudo.

Em seguida, foi feito um contato presencial com as empresas participantes para a entrega do Termo de Consentimento Livre e Esclarecido e agendado um dia para a aplicação do questionário estruturado com questões abertas e fechadas que deveria ser preenchido para cada funcionário com algum tipo de deficiência.

Todos os dados coletados foram digitados em um banco de dados do Excel versão do Microsoft Word 2007. Para caracterizar o perfil da pessoa com deficiência no mercado de trabalho no que diz respeito ao tipo de deficiência, qualificação profissional, nível de escolaridade e ocupações atuais no mercado de trabalho foram feitas análises quantitativas, com enfoque descritivo, o qual tem por base: " coletar dados que mostrem um evento, uma comunidade, um fenômeno, feito, contexto ou situação que ocorre (COLLADO, LÚCIO e SAMPIERE, 2006).

\section{Resultados e discussão}

\subsection{Tipo de deficiência e mercado de trabalho}

A condição mais evidenciada no nosso estudo foi a deficiência auditiva seguida da deficiência física, visual, mental e múltipla. A figura abaixo exemplifica essa questão: 


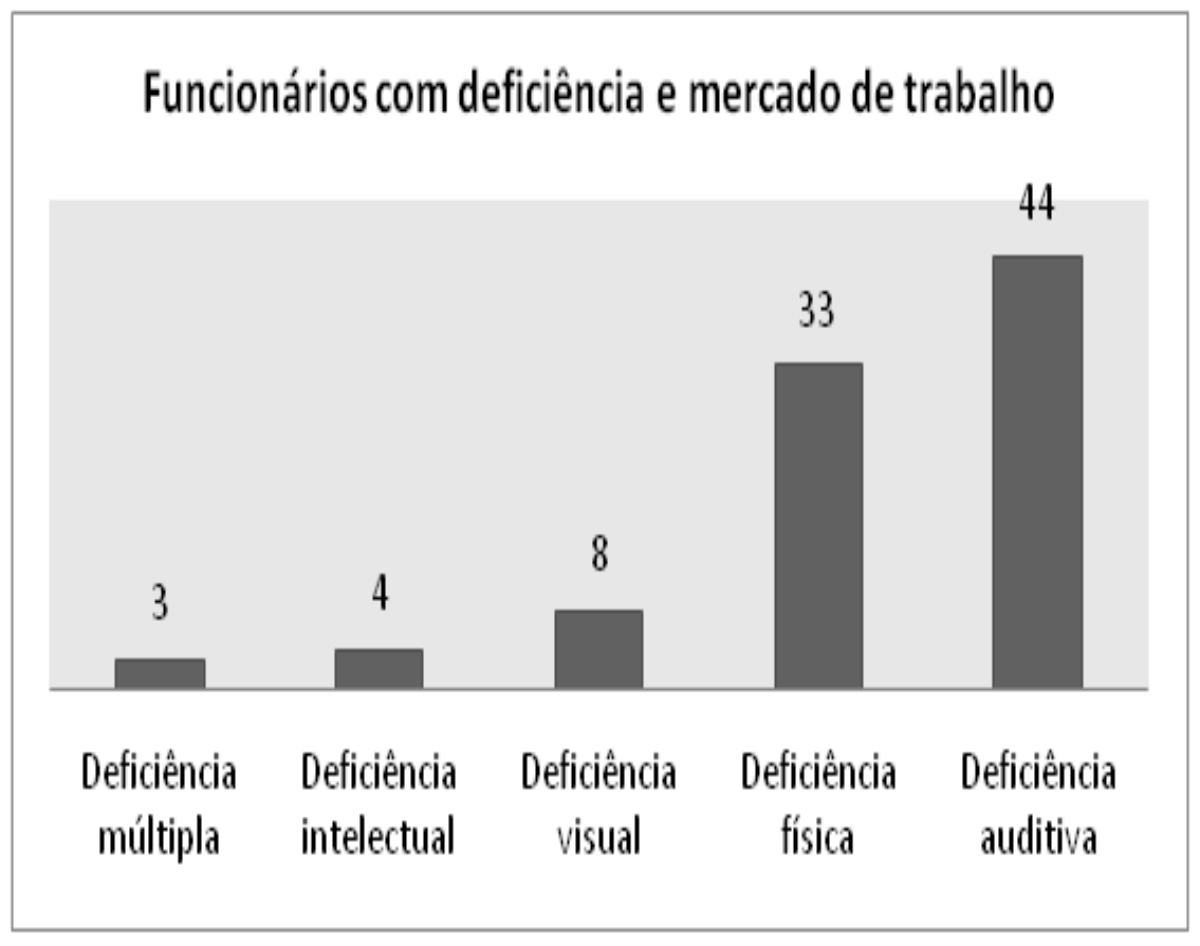

Figura 1. Funcionários com deficiência e mercado de trabalho

A figura 1 indica que $44 \%$ dos funcionários possuem deficiência auditiva, 33\% deficiência física, 8\% deficiência visual, 4 \% deficiência intelectual e $3,2 \%$ deficiência múltipla.

Considerando que cada tipo de deficiência possui características diferenciadas que são importantes para se compreender o ingresso da pessoa com deficiência no mercado de trabalho, a tabela abaixo exemplifica as características encontradas neste estudo para cada condição de deficiência: 
Quadro 2. Características dos participantes de acordo com as diferentes categorias de deficiência

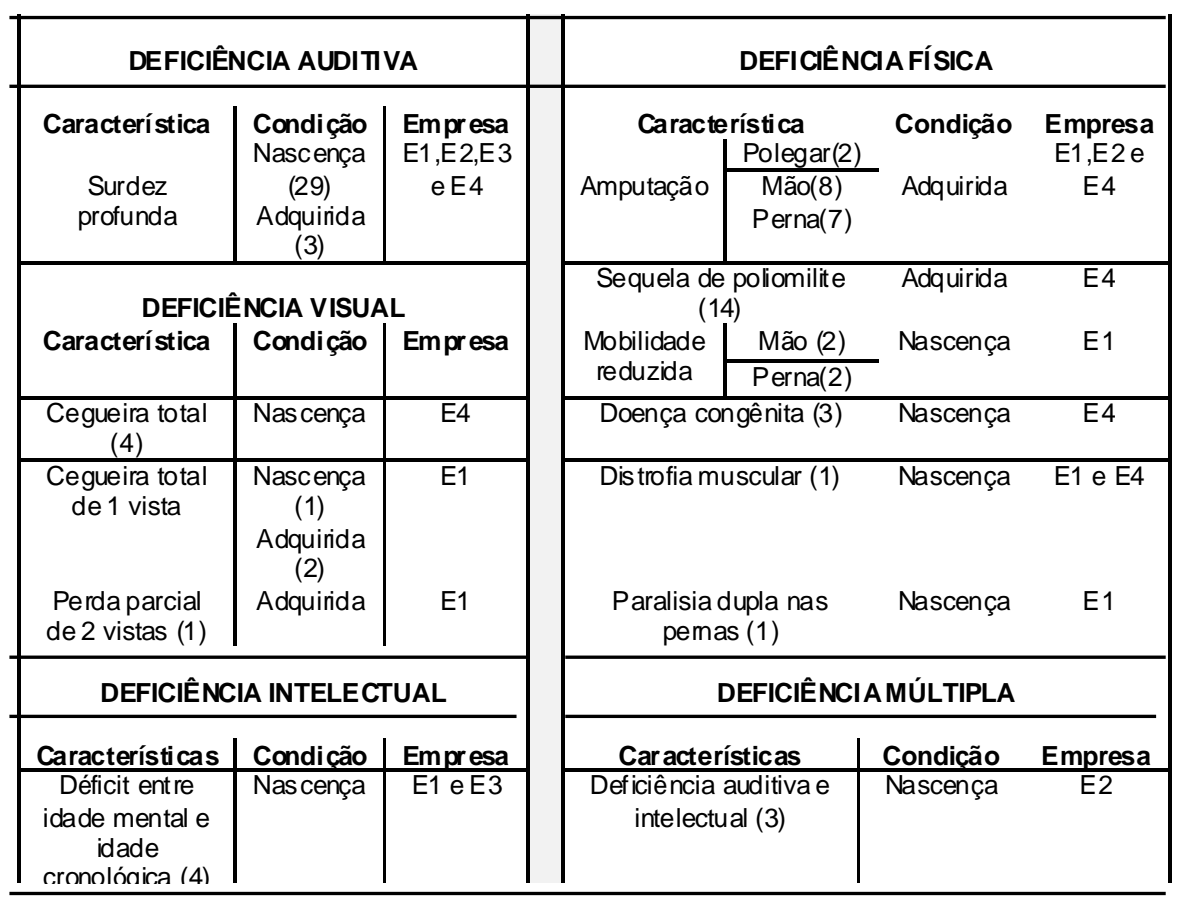

O quadro 2 revela que todos os participantes com deficiência auditiva possuem surdez profunda. Mesmo com esta condição, são as pessoas que mais ingressam no mercado de trabalho em São Carlos/SP. Estes dados corrobaram com os resultados de Lanceloti (3003) ao afirmar que as pessoas com deficiência auditiva são o segundo maior grupo de pessoas com deficiência que ingressam no mercado de trabalho, perdendo apenas para as pessoas com deficiência física.

Pode-se questionar se este fato não está relacionado à necessidade de pouca reestruturação em termos do espaço físico por parte das empresas na contratação da pessoa com deficiência auditiva. Esta hipótese se confirma na medida em que os participantes deste estudo afirmaram que a única alteração feita para receber o funcionário com deficiência auditiva foi fornecer um uniforme diferenciado para evitar acidentes de trabalho.

Com relação às pessoas com deficiência física, as características, em geral, não são muito comprometedoras e nem exigem grande reestruturação por parte da empresa. 
Lanciloti (2003) afirma que as pessoas com deficiência física têm um alto índice de ingresso no mercado de trabalho devido ao fato de que possuem um maior nível de escolaridade. Contudo, diante dos dados apresentados neste estudo, levantamos a hipótese de que provavelmente o índice elevado de pessoas com deficiência física ingressantes no mercado de trabalho é devido às suas características pouco comprometedoras, tais como a amputação de um membro do corpo (dedo, mão), que exigem pouca, ou nenhuma, reestruturação por parte da empresa.

Já com relação a pessoas com deficiência visual, intelectual e múltipla encontramos poucos trabalhadores. A empregabilidade da pessoa com deficiência visual pode estar comprometida devido à necessidade de reestruturação do ambiente, em especial de orientação e mobilidade.

No caso específico da deficiência intelectual, os dados de estudos anteriores (BRADY, 2002; FERREIRA et al, 2004; ARAÚJO, ESCOBAL e GOYOS, 2006) já evidenciavam a baixa empregabilidade das pessoas com deficiência mental, devido a sua baixa escolarização e baixa produtividade.

Outra variável considerada na caracterização dos participantes está relacionada à questão do gênero:

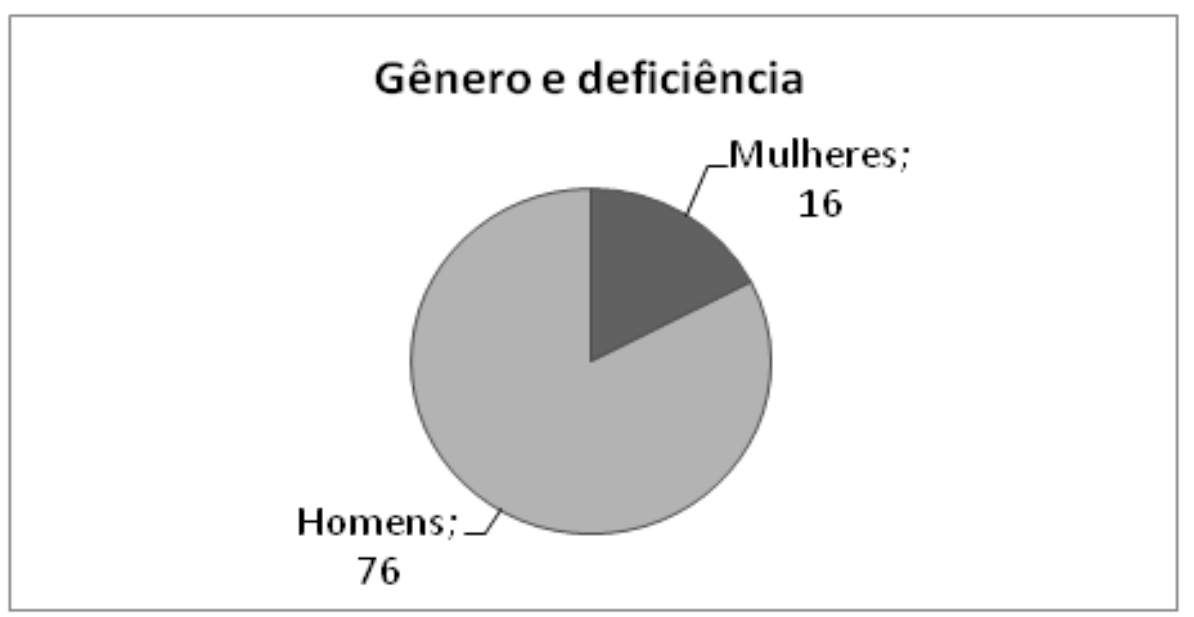

Figura 2. Gênero e deficiência

Na questão de gênero, de acordo com a figura 2, percebe-se que é muito maior o número de homens com deficiência ingressantes no mercado de trabalho em relação às mulheres. Neste estudo, apenas $17 \%$ são mulheres e $83 \%$ são homens. 
A desigualdade nas condições sociais entre homens e mulheres não é recente. Apesar do crescente ingresso da mulher e do maior nível de escolaridade, suas condições de emprego são marcadas por progressos e atrasos, tais como o aumento da participação no mercado de trabalho e conquista de cargos de prestígio, mas também o predomínio em atividades precárias e informais, além de salários mais baixos (BRUSCHINI, 2007).

Indo nesta direção, é importante questionar se existe espaço para mulheres com algum tipo de deficiência que, além da condição da desvantagem social construída relacionada ao gênero, também possuem a desvantagem social de vivenciarem uma condição de deficiência.

\subsection{Escolaridade}

Todos os empregados em condição de deficiência deste estudo são alfabetizados ou, como no caso das pessoas com deficiência intelectual, sabem ao menos assinar o nome e o cartão de ponto. O gráfico abaixo ilustra 0 nível de escolaridade dos funcionários:

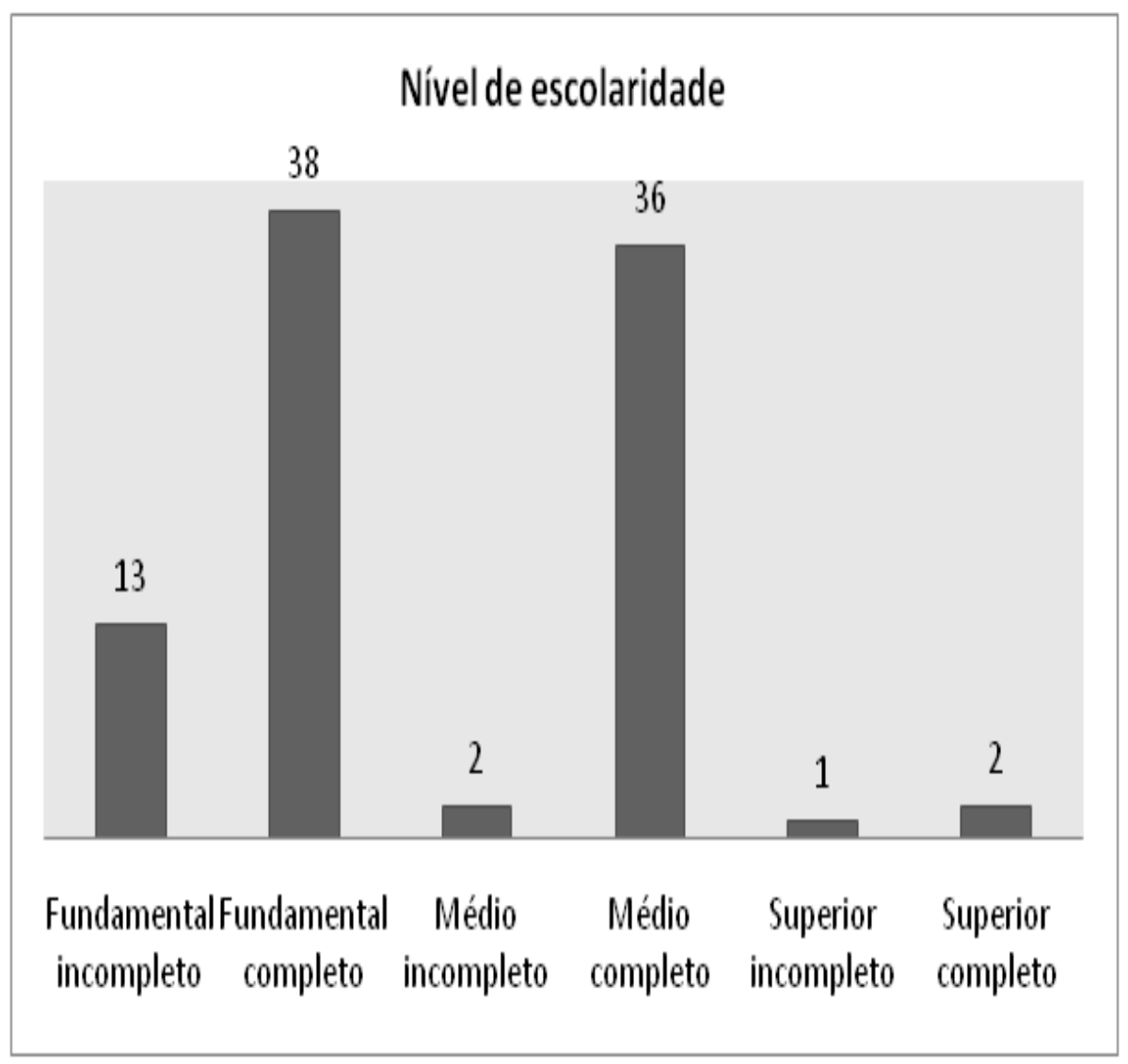

Rev. Educ. Espec., Santa Maria, v. 23, n. 36, p. 73-90, jan./abr. 2010 


\section{Figura 3. Nível de escolaridade}

Os dados dessa figura evidenciam que $11,96 \%$ possui ensino fundamental incompleto e $34,96 \%$ fundamental completo; com relação ao ensino médio, $1,84 \%$ possui o ensino médio incompleto e $33,2 \%$ o ensino médio completo e, no ensino superior, $0,92 \%$ possuem o superior incompleto e $1,84 \%$ o superior completo.Os dados corrobam com de outros estudos (FERREIRA et al, 2004; MANZINI e TANAKA, 2005 e ARAÚJO e SCHMIDT, 2006) ao afirmar que o nível de escolaridade é baixo nas pessoas com deficiência. Do nível de escolaridade ainda é possível fazer relações entre as variáveis, como nível de escolaridade e tipo de deficiência:

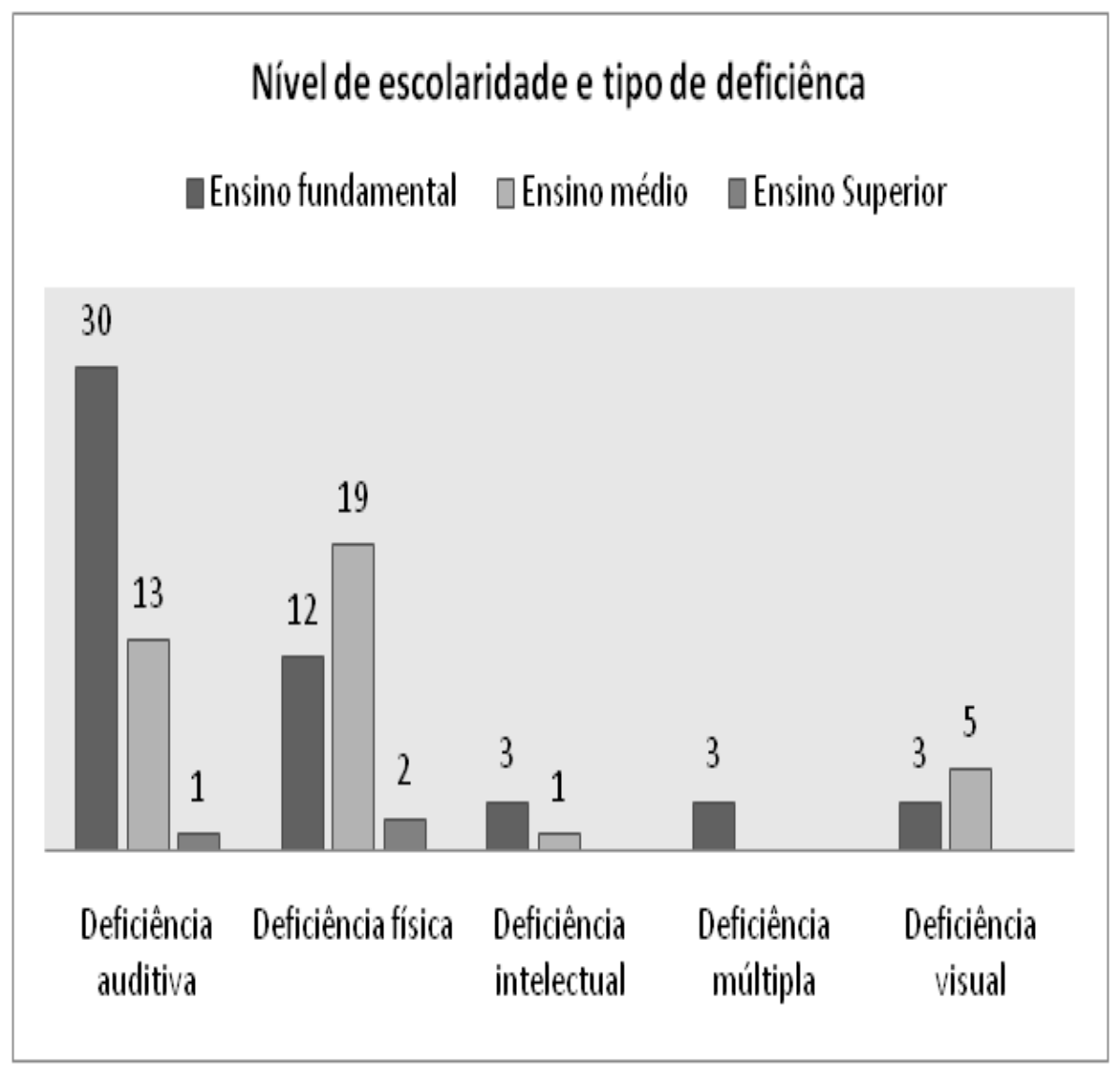

Gráfico 4. Nível de escolaridade e tipo de deficiência 
Com relação ao nível de escolaridade, percebe- se que as pessoas que obtiveram o maior índice de empregabilidade, no caso as pessoas com deficiência auditiva e deficiência física, são as que possuem o maior nível de escolaridade e são as únicas que freqüentaram o ensino superior. As pessoas com deficiência intelectual e deficiência múltipla são as com o menos nível de escolaridade, em que predomina o ensino fundamental. Para Araújo e Schmidt (2006) o maior índice de escolaridade das pessoas com deficiência auditiva, física e visual é em decorrência de que estas deficiências acarretam menos dificuldades no processo de escolarização na educação regular, visto que são deficiências em que é possível encontrar e utilizar recursos para promover a aprendizagem. Além do índice de escolaridade, as empresas contratam mais estas pessoas porque vão ter menores gastos com cursos de capacitação, visto que estas podem participar dos cursos com os demais funcionários da empresa, sem necessitarem de grandes alterações.

É importante identificar o nível de escolaridade, porque, conforme Doval (2006) quanto maior a escolaridade da pessoa em condição de deficiência, assim como sua qualificação profissional, maiores são suas chances de ingressar e permanecer no mercado de trabalho.

\subsection{Ocupação no mercado de trabalho}

Todos os funcionários identificados com algum tipo de deficiência possuem registro em carteira. No que diz respeito à ocupação profissional, percebemos também que a totalidade (exceto um participante com deficiência física que tem o cargo de Químico) exerce funções auxiliares e que exigem pouca qualificação, dados que vão de encontro com os do estudo de Lancelotti (2003) e de Doval (2006). As principais funções identificadas são: auxiliar geral, servente,expedidor de tapetes, preparador de amostra, operador de manufatura, frente de caixa e auxiliar de produção, o que evidencia que na grande maioria das vezes os funcionários com deficiência ocupam cargos auxiliares o que nos leva a discutir a função de se inserir a pessoa com deficiência no mercado de trabalho. Em duas empresas os representantes do setor de recursos humanos afirmaram que as pessoas com deficiência ocupam posições auxiliares porque "não tem condições" de ocuparem posições mais elevadas, as quais exigem um maior nível de qualificação.

\subsection{Adequação do mercado de trabalho}

Com relação à adequação do mercado de trabalho para receber o funcionário com algum tipo de deficiência, a totalidade evidenciou a necessidade de reestruturação. A necessidade decorre especialmente da comunicação envolvendo as pessoas com deficiências sensoriais (deficiência visual e deficiência auditiva). Para estes funcionários, as empresas providenciaram uniformes diferenciados, para garantir a segurança no ambiente de trabalho.

Com relação à condição de deficiência física, as empresas disseram não ter feito nenhuma reestruturação em termos de acessibilidade física, mas 
alegam não terem feito porque ainda não tinham contratado nenhum funcionário cadeirante, por exemplo. No caso das pessoas com deficiência intelectual, as empresa relatam que eles são "bons funcionários", mas ao mesmo tempo admitem que a sua produtividade equivale a "metade de um funcionário", pois o rendimento deles não é o mesmo que o esperado para os demais.

Outro aspecto interessante revelado é a parceria feita entre as empresas e instituições especializadas. A parceria é feita no sentido de garantir que as instituições enviem para as empresas pessoas com deficiência intelectual em condições de ingressarem no mercado de trabalho. Araújo e Schmidt (2006) também identificaram que as instituições especializadas atuavam enquanto parceiras na colocação das pessoas com deficiência no mercado de trabalho e ofereciam programas de acompanhamento para os alunos da instituição que ingressassem no mercado, para garantir o apoio e suporte necessário.

A empresa $\mathrm{E} 4$ tem uma particularidade com relação às demais, na medida em que mudou os critérios de admissão tendo em vista a lei de cotas. Usualmente a empresa só contrata pessoas que tem no mínimo o ensino médio e aplica uma prova de português e matemática aos candidatos para que possam ingressar na empresa. Como as pessoas com deficiência muitas vezes não atendem a estes padrões a empresa criou um critério de admissão "menos exigente" para estes funcionários, em que o nível de exigência para os candidatos com deficiência passou a ser o ensino fundamental em detrimento do ensino médio. Além disso, a prova de português e matemática aborda conteúdos menos exigentes.

A empresa E4 criou também postos de trabalho especiais para as pessoas com deficiência visual, para que estas tivessem maior segurança no ambiente em que atuavam . A empresa também oferece um curso de "sensibilização" e "apadrinhamento" para os funcionários ingressantes. O curso de "sensibilização" tem como objetivo promover atitudes positivas por parte dos funcionários da empresa de aceitação e respeito com as pessoas com deficiência e o "apadrinhamento" consiste em selecionar um funcionário da empresa para que este possa acompanhar o novo funcionário com deficiência, auxiliandoo quando for necessário até que este aprenda as funções da empresa de maneira satisfatória.

Diante disso, pode-se considerar que os apoios para o acesso e permanência da pessoa com deficiência no mercado de trabalho são considerados importantes. No estudo de Manzini e Tanaka (2005) os autores constataram que os empregadores acreditam na importância do apoio e da adaptação da empresa para que esta possa atender as necessidades específicas dos funcionários com deficiência.

\section{Considerações finais}

O estudo permitiu identificar algumas tendências e particularidades do ingresso da pessoa com deficiência no mercado de trabalho no município de São Carlos-SP. 
Em primeiro lugar, identificou-se a tendência em se empregar pessoas com deficiência auditiva e deficiência física. No caso das pessoas com deficiência física, existe uma tendência em empregar as menos comprometidas, tais como as que têm algum membro amputado. A empregabilidade das pessoas com deficiência visual, intelectual e múltipla é ainda feita de maneira muito tímida. Uma possível explicação para este fenômeno é que as empresas empregam apenas aquelas que exigem a menor reestruturação possível. Outra tendência é a baixa escolaridade das pessoas com deficiência e, consequentemente, a ocupação em postos de trabalhos apenas com funções auxiliares.

Algumas particularidades evidenciadas foram a de que temos algumas ações que evidenciam que as empresas estão tentando se adequar à inclusão social das pessoas com deficiência no mercado de trabalho, criando estratégias diferenciadas de admissão e permanência. No entanto, os resultados indicam que para que a pessoa com deficiência possa ser inserida no mercado de trabalho, é preciso apresentar as qualidades exigidas por este, tais como escolaridade, produtividade e competitividade e, além disso, o seu ingresso deve demandar a menor estruturação possível por parte das empresas.

A inclusão no mercado de trabalho não pode ser vista de maneira ingênua. Neste caso, não basta cumprir com os dispositivos éticos e morais da proposta da inclusão, é preciso de fato oferecer para as empresas um profissional "preparado". As instituições que atendem as pessoas com deficiência e que tem como objetivo seu ingresso no mercado de trabalho devem preparar este profissional para que ele desenvolva as características esperadas e possa ingressar de maneira bem-sucedida no mercado de trabalho.

\section{Referências}

AMARAL, L, A. Mercado de trabalho e deficiência. Revista Brasileira de Educação Especial. Piracicaba, n. 2, 1994.

ALOISI, H.M. O empregado com deficiência segundo o conceito empregador da pequena, média e grande empresa na cidade de Campinas. 201p. 1999. Tese (Doutorado em Educação) Universidade Estadual de Campinas, Campinas, 1999.

ARAÚJO, E, C.; ESCOBAL, G.; GOYOS, C. Programa de suporte comunitário: alternativa para o trabalho do adulto deficiente mental. Revista Brasileira de Educação Especial, Marília, v. 12, n. 2, p. 221-240, ago. 2006.

ARAÚJO, J, P.; SCHMIDT, A. A inclusão de pessoas com necessidades especiais no trabalho: a visão de empresas e de instituições educacionais especiais na cidade de Curitiba. Revista Brasileira de Educação Especial, Marília, v. 12, n. 2, p. 241-254, ago. 2006. 
BRADY, M, P., ROSENBERG, H. Job observation and behavior scale: a supported employment assessmnent instrument. Education and training mental retardation and developmental disabilities, v. 37, n. 4, p. 433-427, 2002.

BRASIL. Secretária Especial dos direitos humanos. Decreto n. 3.298, de 20 de dezembro de 1999. Brasília: CORDE, 1999.

BRASIL. Constituição da República Federativa do Brasil. Brasília, DF, 1988.

BRASIL. Secretaria Especial dos direitos humanos. Decreto n. 3.298, de 20 de dezembro de 1999. Brasília: CORDE, 1999.

BRASIL.Secretaria Especial dos direitos humanos. Trabalho e emprego: instrumentos de construção da identidade pessoal e social. Brasília, 2003.

BRUSCHINI, M, C, A. Trabalho e gênero no Brasil nos último dez anos. Cadernos de Pesquisa, v. 37, n. 132, p. 537-572, set./dez. 2007.

COLLADO, C, F; LUCIO, P, B; SAMPIERE, R, H. Metodologia da Pesquisa, McGraw-Hill, São Paulo: 2006.

DOVAL, J, L, M. Inclusão de pessoas portadoras de deficiência no mercado de trabalho: desafios e tendências. 199p.2006. Dissertação (Mestrado em Administração) - Universidade Federal do Rio Grande do Sul, Porto Alegre, 2006.

FERREIRA, J, R et al. Estado da arte das pesquisas sobre profissionalização do portador de deficiência. Temas em Psicologia, (Ribeirão Preto), v. 12, n. 1 , p. 1-20, 2006.

IBGE.INSTTUTO BRASILIEIRO DE GEOGRAFIAE ESTATÍSTICA. Estrutura empresarial do município de São Carlos, 2008. Disponível em: <http:// www.ibge.gov.br/cidadesat/topwindow.htm?1> Acesso em: fev. 2009.

JANUZZI, G, S de M. A educação do deficiente no Brasil: dos primórdios ao início do século XXI. Campinas, SP: Autores Associados, 2004.

LANCILLOTTI, S,S, P. Deficiência e trabalho: redimensionando o singular no contexto universal. Campinas, SP: Autores Associados, 2003.

MANZINI, E, J., TANAKA, E, D, O. O que os empregadores pensam sobre o trabalho da pessoa com deficiência? Revista Brasileira de Educação Especial, Marília, v.12, n.2, p.273-294, ago. 2006.

RAGAZZI, C, M, L. Emprego com apoio: alternativa viável para inserção de pessoas com deficiência mental no mercado de trabalho? 100 p. 2001. Dissertação (Mestrado em Educação Especial). Centro de Educação e Ciências Humanas. Universidade Federal de São Carlos, São Carlos, 2006.

REDONDO, M, C, F., O deficiente auditivo e o mercado de trabalho. $183 \mathrm{p}$. 1990. Dissertação (Mestrado em Educação) - Pontifícia Universidade Católica de São Paulo,São Paulo, 1990. 
SILVA, A, G. A educação profissional de pessoas com deficiência mental: a história da relação educação especial -trabalho na APAE-SP. 260p. 2000. Tese (Doutorado em Educação) - Universidade Estadual de Campinas, Campinas, 2000.

TANAKA, E, D, O. O desenvolvimento de uma escala de atitudes sociais em relação ao trabalho da pessoa com deficiência. 198p. 2007. Tese (Doutorado em Educação) - Universidade Estadual Paulista Júlio de Mesquita Filho, Marília, 2007.

Notas

${ }^{1}$ Universidade de São Paulo-USP e Universidade Federal de São Carlos-UFSCar.

\section{Correspondência}

Aline Aparecida Veltrone - Rua Campos Salles 188, CEP: 13560-350. Vila Elizabeth, São Carlos (SP).

E-mail: aline_veltrone@hotmail.com

Recebido em 13 de novembro de 2009

Aprovado em 12 de janeiro de 2010 
